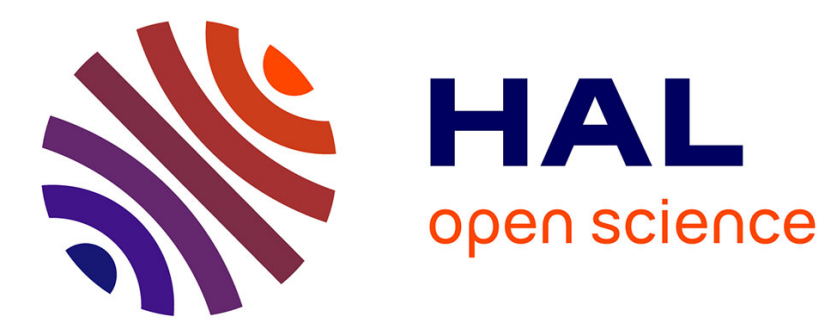

\title{
Laminar burning velocity of gasolines with addition of ethanol
}

Patricia Dirrenberger, Pierre-Alexandre Glaude, Roda Bounaceur, Hervé Le Gall, Antonio Pires da Cruz, Alexander Konnov, Frédérique Battin Leclerc

\section{- To cite this version:}

Patricia Dirrenberger, Pierre-Alexandre Glaude, Roda Bounaceur, Hervé Le Gall, Antonio Pires da Cruz, et al.. Laminar burning velocity of gasolines with addition of ethanol. Fuel, 2014, 115, pp.162169. 10.1016/j.fuel.2013.07.015 . hal-00853563

\section{HAL Id: hal-00853563 https://hal.science/hal-00853563}

Submitted on 22 Aug 2013

HAL is a multi-disciplinary open access archive for the deposit and dissemination of scientific research documents, whether they are published or not. The documents may come from teaching and research institutions in France or abroad, or from public or private research centers.
L'archive ouverte pluridisciplinaire HAL, est destinée au dépôt et à la diffusion de documents scientifiques de niveau recherche, publiés ou non, émanant des établissements d'enseignement et de recherche français ou étrangers, des laboratoires publics ou privés. 


\section{LAMINAR BURNING VELOCITY OF GASOLINES WITH}

\section{ADDITION OF ETHANOL}

P. Dirrenberger ${ }^{1}$, P.A. Glaude ${ }^{*}$, R. Bounaceur ${ }^{1}$, H. Le Gall ${ }^{1}$, A. Pires da Cruz $^{2}$, A.A. Konnov ${ }^{3}$,

F. Battin-Leclerc ${ }^{1}$

${ }^{1}$ Laboratoire Réactions et Génie des Procédés, CNRS, Université de Lorraine

1 rue Grandville, BP 20451, 54001 Nancy Cedex, France

${ }^{2}$ IFP Energies nouvelles, 1 et 4 avenue de Bois Préau, 92852 Rueil-Malmaison, France

${ }^{3}$ Division of Combustion Physics, Lund University, Lund, Sweden

*Corresponding author:

Email: pierre-alexandre.glaude@ensic.inpl-nancy.fr

LRGP, 1 rue Grandville, BP 20451, 54001 Nancy Cedex, France

Phone: +33 383175101

Fax: + 33383322975

\section{1 supplementary file}




\title{
LAMINAR BURNING VELOCITY OF GASOLINES WITH
}

\section{ADDITION OF ETHANOL}

\author{
P. Dirrenberger ${ }^{1}$, P.A. Glaude $*^{1}$, R. Bounaceur ${ }^{1}$, H. Le Gall ${ }^{1}$, A. Pires da Cruz $^{2}$, A.A. Konnov ${ }^{3}$, \\ F. Battin-Leclerc ${ }^{1}$ \\ ${ }^{1}$ Laboratoire Réactions et Génie des Procédés, CNRS, Université de Lorraine \\ 1 rue Grandville, BP 20451, 54001 Nancy Cedex, France \\ ${ }^{2}$ IFP Energies nouvelles, 1 et 4 avenue de Bois Préau, 92852 Rueil-Malmaison, France \\ ${ }^{3}$ Division of Combustion Physics, Lund University, Lund, Sweden
}

\begin{abstract}
The adiabatic laminar burning velocities of a commercial gasoline and of a model fuel (n-heptane, iso-octane, and toluene mixture) of close research octane number have been measured at $358 \mathrm{~K}$. Non-stretched flames were stabilized on a perforated plate burner at 1 atm. The heat flux method was used to determine burning velocities under conditions for which the net heat loss of the flame is zero. Very similar values of flame velocities have been obtained for the commercial gasoline and for the proposed model fuel. The influence of ethanol as an oxygenated additive has been investigated for these two fuels and has been found to be negligible for values up to $15 \%$ (vol). Measurements were also performed for ethanol and the three pure components of the model fuel at 298, 358 and $398 \mathrm{~K}$. The results obtained for the studied mixtures, and for pure $n$-heptane, iso-octane, toluene and ethanol, have been satisfactorily simulated using a detailed kinetic mechanism.
\end{abstract}

Keywords: Laminar burning velocity, gasoline, $n$-heptane, iso-octane, toluene, ethanol. 


\section{INTRODUCTION}

Laminar burning velocities are important parameters in many areas of combustion science such as the design of burners or engines and for the prediction of explosions. While numerous studies have been performed to measure the laminar burning velocity of mixtures containing hydrogen, methane and to a lesser extend hydrocarbons from $C_{2}$ to $C_{3}$, there are much less data available concerning fuels with a low vapor pressure (i.e. liquids under standard conditions). The most studied compounds amongst hydrocarbons containing more than four carbon atoms are n-heptane and iso-octane, which are the primary reference fuels for octane rating in spark-ignited internal combustion engines. (e.g. [1-20]). Among them, several studies concerned also binary mixtures of these two compounds (PRF mixtures, e.g.[10][11][20]). Toluene is often used as a surrogate of the aromatic moiety of fuels, and few measurements of its laminar burning velocities have been presented [21][22][23][24] To our knowledge, only two studies were performed with commercial gasolines [20][25]. Jerzembeck et al. [20] have shown that the laminar flame velocity properties of a commercial gasoline can be satisfactorily matched by a PRF mixture with a research octane number (RON) of 87 . However, while the agreement was very good for lean mixtures, deviations were observed for stoichiometric and rich mixtures. A first purpose of this study is then to experimentally investigate if the use of a ternary mixture (a PRF mixture including toluene) can better match the laminar burning velocity of a commercial gasoline.

The current atmospheric issues have led to an increasing interest to shift from hydrocarbon fossil fuels to bio-fuels, particularly ethanol in the case of gasoline [26]. Ethanol is indeed an attractive renewable alternative fuel with a high octane number (RON/MON=120/99)[27]. This explains why a larger number of studies of the laminar burning velocity of ethanol have been published in recent years ([15],[18][19],[28]-[35]). Two studies have been published about a mixture of a large alkane (iso-octane) and ethanol [34][35], and one about a mixture of ethanol 
and PRF [36]. Since ethanol is an alternative as well as complementary fuel to gasoline of increasing importance, the second purpose of this study is then to characterize the influence of the addition of ethanol on the laminar burning velocity properties of a commercial gasoline and of the ternary mixture proposed to represent it. Finally, a model is proposed to simulate laminar burning velocities of the mixtures investigated in this study, as well as of each component taken separately.

\section{EXPERIMENTAL FACILITY}

The measurements of laminar burning velocities were performed using a recently built flat flame adiabatic burner. This apparatus has already been used for measuring laminar burning velocities in the case of components and surrogate mixtures of natural gases [37] and diethylether [38]. It is based on the heat flux burner developed by the group of de Goey [39]. The apparatus consists of a burner head mounted on a plenum chamber. The burner head is a thin perforated plate made of brass of $30 \mathrm{~mm}$ diameter which is used to stabilize the flame. Each small hole of the plate has a $0.5 \mathrm{~mm}$ diameter and the pitch between the holes is $0.7 \mathrm{~mm}$. Eight type $\mathrm{K}$ thermocouples of $0.5 \mathrm{~mm}$ diameter are soldered into the plate surface and are positioned at different distances and angles from the center to the periphery of the burner. The plenum chamber is encompassed by a thermostatic oil jacket, the temperature of which is set to the desired initial temperature of the unburned gas mixture. The circumference of the burner plate is heated with thermostatic oil set at least to $50 \mathrm{~K}$ above the temperature of the unburned gas mixture. The difference between the temperature of the fresh gases and that of the burner has to be high enough to be able to create a heat flux toward the fresh gases equal to that from the flame toward the burner. Furthermore, a higher temperature gap between the burner and the fresh gases induces steeper temperature variations along the burner diameter with the variation of the gas flow rate, and permits a more precise determination of the adiabatic conditions. Some tests were performed with fresh gases at $298 \mathrm{~K}$ and similar burning velocities were determined for 
different burner plate temperatures, with a difference as low as $40 \mathrm{~K}$. In practice, for a desired initial temperature of $298 \mathrm{~K}$, the temperature of the mixing chamber was set to $298 \mathrm{~K}$ and that of the burner plate to $355 \mathrm{~K}$. For the initial temperature of $385 \mathrm{~K}$ and $398 \mathrm{~K}$, the burner plate temperature was set to $410 \mathrm{~K}$ and $450 \mathrm{~K}$, respectively.

Thus, the heat gain of the unburned gas mixture can compensate for the heat loss necessary for stabilizing the flame, knowing that monitoring of the heat loss or gain is performed with the thermocouples. If the unburned gas velocity is lower than the adiabatic flame burning velocity, the sum of the heat loss and heat gain is higher than zero. Then, the center of the burner plate is hotter than the periphery, and the flame is stabilized under subadiabatic conditions. On the other hand, if the unburned gas velocity is higher than the adiabatic burning velocity, the center of the burner plate is cooler than the periphery and the flame is stabilized under superadiabatic conditions. Thus, when the temperature profile is flat, it means that no heat is lost or gained by the flame so that the flame becomes adiabatic with respect to the burner. By changing the flow rate of the gas mixture, it is possible to find an appropriate value of the gas velocity to cancel out the net heat flux so that the radial temperature distribution in the burner plate is uniform. The flow rate at which the net heat flux is zero corresponds to the adiabatic flame burning velocity [39].

\section{Figure 1}

For compounds gaseous at room temperature, gas flow rates were measured using Bronkhorst High-Tech Mass Flow Controllers (MFC). For compounds liquid at room temperature, liquid flow rates were measured using Bronkhorst mini-CORI-FLOW Mass Flow Controller. Oxygen and nitrogen were delivered by Messer. Toluene was provided by Rectapur (purity $>99.99 \%$ ), ethanol by Sigma-Aldrich (purity $>99.8 \%$ ), $n$-heptane by Fischer (purity > 99.8\%) and iso-octane by Fluka (purity > 99\%). The commercial gasoline was provided by TOTAL (Reference IFPEN: TAE 7000). 
As the adiabatic laminar burning velocity is found when the net heat loss is zero, the error is only dependent on a few factors. The error in the laminar burning velocity can be attributed to the error in the mass flow measurements (around 0.5\% for each MFC) which can lead to a global error of $1.5 \%$ in the laminar burning velocity, the error in reading the temperature with thermocouples which could lead to an error of around $0.2 \mathrm{~cm} / \mathrm{s}$ in the laminar burning velocity, and to errors due directly to flame distortions, such as edge effects (estimated around $0.2 \mathrm{~cm} / \mathrm{s}$ ). Concerning the calculation of equivalence ratios, note that the main error is due to the error in the mass flow measurements which leads to an error of about $1 \%$. Finally, there are some qualitative errors which are difficult to evaluate such as the possible errors in the fresh gas temperature if the gaseous mixture does not spend enough time in the plenum chamber to uniformly reach the studied unburned gas temperature.

\section{EXPERIMENTAL RESULTS FOR PURE COMPOUNDS}

Laminar flame velocities were measured at 298, 358 and $398 \mathrm{~K}$ for pure $n$-heptane, iso-octane, toluene and ethanol for equivalence ratios ranging 0.6 to 1.8 when high enough vapor pressure was available. When possible the obtained measurements were compared with data from the literature. These results are presented in figures 2 to 5 .

\section{FIGURES 2 TO 5}

Figures 2 and 3 compare our measurements for $n$-heptane and iso-octane to that of the literature. Considering the most recent data, our results are in good agreement at $298 \mathrm{~K}$ with the data of Davis and Law [4], Huang et al. [10] and van Lipzig et al. [36]. At $358 \mathrm{~K}$, our measurements for $n$-heptane are in good agreement with that of $\mathrm{Ji}$ et al. [6] for lean and stoichiometric mixtures but faster for rich mixtures, while burning velocities measured for isooctane are very close to those of Bradley et al. [11]. At 398K, our iso-octane burning velocities agree well with those of Halter et al. [12], Zhou et al. [13] and Li et al. [14]. At the three studied 
temperatures, for both alkanes, our measurements are systematically lower than those of Kumar et al. [16], which are faster than that of the literature whatever the temperature of the fresh gases.

Figure 4 displays the obtained results for toluene, which are in good agreement at $298 \mathrm{~K}$ with the few data from the literature, especially Davis et al. [21], but slightly faster than those of Ji et al. [24] for rich mixtures. In the case of ethanol, which has been recently studied by several groups, our results are shown in Figure 5. Our measurements at 298 and $358 \mathrm{~K}$ are in very good agreement with the recent data found in the literature [29][32][34][36]. A close agreement is observed with the measurements of van Lipzig et al. [36] obtained using the same method.

Figure 6 displays the measurements made for the four studied pure compounds at $358 \mathrm{~K}$. Amongst these four compounds, ethanol is the one with the highest velocities, while iso-octane and toluene are those with the lowest velocities. Very similar values are obtained for these two compounds of large RON. The values obtained for $n$-heptane lie in between those of ethanol, iso-octane and toluene in agreement with observations of van Lipzig et al. [36].

\section{FIGURE 6}

\section{EXPERIMENTAL RESULTS FOR MIXTURES}

Laminar burning velocities have been measured at $358 \mathrm{~K}$ for a commercial gasoline (TAE7000) with a RON close to 95. Analyses have shown that this gasoline is composed of $10.5 \%$ (vol.) of $n$-alkanes, $40.7 \%$ of iso-alkanes and $32.5 \%$ of aromatic compounds, the remaining being cyclic, unsaturated and oxygenated compounds. Measurements have also been performed for a proposed surrogate mixture: a ternary $n$-heptane/iso-octane/toluene blend formulated in order to match the properties of the TAE7000 in terms of auto-ignition properties (RON and MON), $\mathrm{C} / \mathrm{H}$ ratio and normal boiling temperature as shown in Table 1 . The fractions 
of $n$-alkanes and of iso-alkanes are close to those actually present in TAE7000, while the fraction of aromatic compounds (represented by toluene) is slightly larger. The surrogate mixture has already been used in several spark ignition engine experiments made at IFPEN and compared with commercial gasoline. Engine results have shown good agreement in terms of combustion velocity, pollutant emissions and knock behavior.

\section{TABLE 1}

Figure 6 shows a comparison of the laminar burning velocities of TAE7000 with those of the four pure compounds studied. The values obtained for the commercial gasoline are very close to those measured for toluene for equivalence ratios below 0.9 and above 1.2, but slightly higher in between.

Figure 7 displays the measurements for the TAE7000 and its surrogate mixture and shows that both fuels have very close laminar burning velocities for complete range of the studied equivalence ratios (i.e. from 0.6 to 1.5). The peak of laminar burning velocity is also in good agreement between both fuels. The largest deviation is obtained close to the maximum for the equivalence ratio of 1.1 and is of $\sim 2 \mathrm{~cm} / \mathrm{s}$. Despite the limited range of thermodynamic conditions of the present experiment, the match between both fuels is a good support of the similar results obtained in the engine.

\section{FIGURE 7}

In order to study the influence of the addition of ethanol on the laminar burning velocities of TAE7000 and of its surrogate, measurements have been made for mixtures of these two blends containing also 15\% (vol.) of ethanol. The results are shown in figure 8 . While the addition of ethanol increases the RON value of the studied mixture above 100 (see Table 1) and while ethanol alone shows the largest values of the laminar burning velocities amongst the four studied compounds, the addition of $15 \%$ of ethanol has no effect both on the laminar burning velocities of TAE7000 and on those of its surrogate. 


\section{FIGURE 8}

A table of experimental values obtained for the laminar burning velocities of all studied neat compounds and mixtures with the associated errors (corresponding to error bars in the related figures) is given as supplementary electronic material.

\section{MODELING}

The detailed kinetic mechanisms used in this study for alkanes have been automatically generated by the computer package EXGAS, which has been developed for several years to automatically generate detailed kinetic models for the gas-phase oxidation and combustion of the main components of gasolines, diesel fuels and biofuels [40][41]. In the case of toluene, a newly developed mechanism [42], which was based on that of Bounaceur et al. [43], has been used. To model the behaviour of the gasoline surrogate, the mechanism for toluene has been coupled to the one automatically generated for a $n$-heptane/iso-octane-mixture.

We will recall here very briefly the main features of EXGAS, which has been described in more detail previously [40][41]. The system provides reaction mechanisms made of three parts. (1) A comprehensive primary mechanism, where the only molecular reactants considered, are the initial organic compounds and oxygen. The following reactions are considered:

- From the initial reactants: unimolecular initiations involving the breaking of C-C and C-H bonds; bimolecular initiations with oxygen to produce alkyl and $\mathrm{HO}_{2}$ radicals, and metatheses involving $\mathrm{H}$-atom abstractions by small radicals;

- From alkyl radicals: isomerizations and oxidations with $\mathrm{O}_{2}$ to form alkenes and $\mathrm{HO}_{2}$ radicals (the fact that the additions of alkyl radicals to oxygen molecules and the subsequent reactions, which are only important below $1000 \mathrm{~K}$, are not considered allows the mechanisms to keep a limited size compatible with laminar flame speed computations); 
- From all radicals: decompositions of radicals by $\beta$-scission involving the breaking of $\mathrm{C}-\mathrm{C}$, C-O or C-H bonds.

(2) $A C_{0}-C_{2}$ reaction base, including all the reactions involving radicals or molecules containing less than three carbon atoms. The fact that no generic rule can be derived for the generation of the reactions involving very small compounds makes the use of this reaction base necessary. Note that the reactions of ethanol are included in this reaction base.

(3) A lumped secondary mechanism, containing the reactions consuming the molecular products of the primary mechanism, which do not react in the reaction base. To reduce the number of reactants in the secondary mechanism, the molecules formed in the primary mechanism, with the same molecular formula and the same functional groups, are lumped into one unique species, without distinguishing between the different isomers. The reactions of the lumped products are globalized [41].

The model for the oxidation of toluene includes the following sub-mechanisms [43]:

- A primary mechanism including reactions of toluene as well as reactions of toluene and benzyl, tolyl (methylphenyl), peroxybenzyl, alcoxybenzyl and cresoxy free radicals.

- A secondary mechanism involving the reactions of benzaldehyde, benzylhydroperoxyde, cresol, benzylalcohol, ethylbenzene, styrene and bibenzyl.

- A mechanism for the oxidation of benzene including the reactions of benzene and of cyclohexadienyl, phenyl, phenylperoxy, phenoxy, hydroxyphenoxy, cyclopentadienyl, cyclopentadienoxy and hydroxycyclopentadienyl free radicals, as well as the reactions of ortho-benzoquinone, phenol, cyclopentadiene, cyclopentadienone and vinylketene.

- A mechanism for the oxidation of unsaturated $\mathrm{C}_{0}-\mathrm{C}_{4}$ species, which contains reactions involving $\bullet \mathrm{C}_{3} \mathrm{H}_{2}, \cdot \mathrm{C}_{3} \mathrm{H}_{3}, \mathrm{C}_{3} \mathrm{H}_{4}$ (allene and propyne), $\bullet \mathrm{C}_{3} \mathrm{H}_{5}$ (three isomers), $\mathrm{C}_{3} \mathrm{H}_{6}, \mathrm{C}_{4} \mathrm{H}_{2}$, $\cdot \mathrm{C}_{4} \mathrm{H}_{3}$ (2 isomers), $\mathrm{C}_{4} \mathrm{H}_{4}, \cdot \mathrm{C}_{4} \mathrm{H}_{5}$ (5 isomers), $\mathrm{C}_{4} \mathrm{H}_{6}$ (1,3-butadiene, 1,2-butadiene, methylcyclopropene, 1-butyne and 2-butyne). 
This mechanism for the oxidation of toluene has been validated in previous work using experimental results obtained in jet stirred and plug flow reactors and in shock tubes [42][43].

Thermochemical data for molecules or radicals were calculated and stored as 14 polynomial coefficients, according to the CHEMKIN formalism [44]. These data were mostly calculated using software THERGAS [45], based on the group and bond additivity methods proposed by Benson [46]. The transport properties were used for the evaluation of gas-phase multicomponent viscosities, thermal conductivities, diffusion coefficients, and thermal diffusion coefficients and were defined in CHEMKIN format [44]. For the species for which it was possible, we considered the values of transport data issued from the literature and common to many chemical models. For the other species, we have used a correlation with the molecular weight proposed by Wang and Frenklach [47].

The Premix code from the CHEMKIN Collection [44] is used for the flame modelling. Multicomponent diffusion and thermal diffusion options were taken into account. The complete model involves 304 species and 2234 reactions and is available on request.

Figures 2 and 3 show the comparison between simulations and experimental results for $n$-heptane and iso-octane. In both cases, the agreement is satisfactory for lean, stoichiometric mixtures and moderately rich mixtures, but the burning velocities are underpredicted for equivalence ratios above 1.3. As shown in figure 4, the agreement is very good for toluene on the whole range of equivalence ratio, with the shape of the evolution of the burning velocity better reproduced by the model than in the case of alkanes. The under prediction of burning velocities of the non-aromatic fuels in the richest conditions seems to be linked to intermediates, which are not so sensitive in the case of toluene. Some tests have shown the high sensitivity of some reactions of ethylene and unsaturated $\mathrm{C}_{4}$ molecules such as 1,3-butadiene $\mathrm{C}_{4} \mathrm{H}_{6}$ and vinylacetylene $\mathrm{C}_{4} \mathrm{H}_{4}$. These species are yielded in large amount during the combustion of ethanol, linear and branched alkanes but are of minor importance in the combustion pathways of 
toluene. In rich conditions, the role of H-atoms is enhanced and the competition between the addition on unsaturated bonds of small hydrocarbons and the branching reaction $\mathrm{H}+\mathrm{O}_{2}=\mathrm{OH}+\mathrm{O}$ becomes very sensitive. The sub-mechanisms for the combustion of ethylene and $\mathrm{C}_{4}$ should be revised in rich conditions but this development is beyond the scope of the present work.

Figure 5 shows the comparison between simulations and experimental results for ethanol. In this case, a mechanism newly developed in our team and validated against premixed flame structure and laminar burning velocities has been used [48]. The burning velocities are well reproduced, with a small under-prediction for rich mixtures when the fresh gas temperature increases.

Figures 7 and 8 present the comparison between simulations and experimental results for the surrogate mixture and the surrogate mixture with ethanol. In both cases, the obtained agreement is very good. Note however that the agreement between experimental values and simulation is still better for real gasoline mixtures than for model fuels.

\section{CONCLUSION}

New experimental measurements have been performed by the heat flux method using a flat flame adiabatic burner at atmospheric pressure. Laminar burning velocities as a function of the equivalence ratio have been measured in the case of pure ethanol, toluene, $n$-heptane and iso-octane, these last two compounds being primary reference fuels for octane number rating. A commercial gasoline and a proposed model fuel (a $n$-heptane/iso-octane/toluene mixture) have also been studied, showing that the ternary mixture is a very good surrogate of the commercial gasoline in terms of laminar burning velocity representation. The influence of ethanol as an oxygenated additive has been investigated. Mixtures of $15 \%$ of ethanol with the commercial gasoline and its surrogate have been studied, showing a negligible influence of the addition of the oxygenated compound. A detailed kinetic model leads to good predictions for pure 
hydrocarbons and for the commercial gasoline; improvements are still needed in the case of rich mixtures, but that is also the case of the other models in literature.

\section{ACKNOWLEDGEMENTS}

This work was funded by the Région Lorraine in the project "Procédes Propres et Développement Durable" of the program "Matériaux-Energie-Procédés-Produits". 


\section{REFERENCES}

[1] Gerstein M, Levine O, Wong EL, Flame Propagation. II. The determination of fundamental burning velocities of hydrocarbons by a revised tube method, Journal of the American Chemical Society, 1951, 73:418-422.

[2] Heimel S., Weast R.C. Effect of initial mixture temperature on the burning velocity of benzene-air, n-heptane-air, and iso-octane-air mixtures, Symposium (International) on Combustion, 1956, 6:296-302.

[3] Gibbs G.J., Calcote H.F. Effect of molecular structure on burning velocity, J Chem Eng Data, 1959, 4:226-237.

[4] Davis SG, Law CK. Laminar flame speeds and oxidation kinetics of iso-octane-air and nheptane-air flames. Symposium (International) on Combustion. 1998;27:521-527.

[5] Kwon O.C., Hassan M.I., Faeth G.M. Flame/stretch interactions of premixed fuelvapor/O $/ \mathrm{O}_{2} / \mathrm{N}_{2}$ Flames, J. Propul. Power, 2000, 16:513-522.

[6] Ji C., Dames E., Wang Y.L., Wang H., Egolfopoulos F.N. Propagation and extinction of premixed $\mathrm{C}_{5}-\mathrm{C}_{12}$ n-alkane flames, Combust. Flame, 2010, 157:277-287.

[7] Kelley A.P., Liu W., Xin Y.X., Smallbone A.J., Law C.K. : Laminar flame speeds, nonpremixed stagnation ignition, and reduced mechanisms in the oxidation of iso-octane, Proc. Combust. Inst., 2011, 33:501-508.

[8] Gülder O.L. Laminar burning velocities of methanol, ethanol and iso-octane-air mixtures, Symposium (International) on Combustion, 1982, 19:275-281.

[9] Metghalchi M., Keck J.C. Burning velocity of mixtures of air with methanol, isooctane, and indolene at high pressure and temperature, Combust. Flame, 1982, 48, 191-210.

[10] Huang Y, Sung CJ, Eng JA. Laminar flame speeds of primary reference fuels and reformer gas mixtures. Combust Flame. 2004;139(3):239-251. 
[11] Bradley D, Hicks RA, Lawes M, Sheppard CGW, Woolley R. The Measurement of Laminar Burning Velocities and Markstein Numbers for Iso-octane-Air and Iso-octane-nHeptane-Air Mixtures at Elevated Temperatures and Pressures in an Explosion Bomb. Combust Flame. 1998;115(1-2):126-144.

[12] Halter F., Tahtouh T., Mounaïm-Rousselle C. Nonlinear effects of stretch on the flame front propagation, Combust Flame. 2010, 157:1825-1832.

[13] Zhou J.X., Cordier M., Mounaïm-Rousselle C., Foucher F. Experimental estimate of the laminar burning velocity of iso-octane in oxygen-enriched and $\mathrm{CO}_{2}$-diluted air, Combust Flame. 2011, 158:2375-2383.

[14] Li Q., Fu J., Wu X., Tang C., Huang Z. Laminar flame speeds of DMF/iso-octane-air$\mathrm{N}_{2} / \mathrm{CO}_{2}$ mixtures, Energy \& Fuels. 2012 26: 917-925.

[15] Farrell JT, Johnston RJ, Androulakis IP. Molecular structure effects on laminar burning velocities at elevated temperature and pressure. SAE paper. 2004-01-2936.

[16] Kumar K., Freeh J.E., Sung C.J., Huang Y. : Laminar flame speeds of preheated isooctane $/ \mathrm{O}_{2} / \mathrm{N}_{2}$ and n-heptane/ $\mathrm{O}_{2} / \mathrm{N}_{2}$ mixtures, J. Propul. Power, 2007, 23:428-436.

[17] Smallbone AJ, Liu W, Law CK, You XQ, Wang H. Experimental and modeling study of laminar flame speed and non-premixed counterflow ignition of n-heptane. Proc Combust Inst. 2009;32(1):1245-1252.

[18] Marshall SP, Taylor S, Stone CR, Davies TJ, Cracknell RF. Laminar burning velocity measurements of liquid fuels at elevated pressures and temperatures with combustion residuals. Combust Flame. 2011;158(10):1920-1932.

[19] Varea E, Modica V, Vandel A, Renou B. Measurement of laminar burning velocity and Markstein length relative to fresh gases using a new postprocessing procedure: Application 
to laminar spherical flames for methane, ethanol and isooctane/air mixtures. Combust Flame. 2012;159(2):577-590.

[20] Jerzembeck S, Peters N, Pepiot-Desjardins P, Pitsch H. Laminar burning velocities at high pressure for primary reference fuels and gasoline: Experimental and numerical investigation. Combust Flame. 2009;156(2):292-301.

[21] Davis S.G., Wang H., Brezinsky K., Law C.K. Laminar flame speeds and oxidation kinetics of benzene-air and toluene-air flames, Symposium (International) on Combustion. 1996, 26:1025-1033.

[22] Hirasawa T, Sung CJ, Joshi A, Yang Z, Wang H, Law CK. Determination of laminar flame speeds using digital particle image velocimetry: Binary Fuel blends of ethylene, n-Butane, and toluene. Proc Combust Institute. 2002;29(2):1427-1434.

[23] Kumar K., Sung C.J. Flame propagation and extinction characteristics of neat surrogate fuel components, Energy \& Fuels, 2010; 24: 3840-3849.

[24]Ji C., Dames E., Wang H., Egolfopoulos F.N. Propagation and extinction of benzene and alkylated benzene flames, Combust Flame. 2012, 159: 1070-1081.

[25]Zhao Z, Conley J, Kazakov A, Dryer F. Burning Velocities of Real Gasoline Fuel at 353 K and 500 K. SAE paper. 2003-01-3265.

[26] Agarwal AK. Biofuels (alcohols and biodiesel) applications as fuels for internal combustion engines. Prog Energy Combust Sci. 2007;33(3):233-271.

[27] Ballerini, D. Les Biocarburants: Etat des Lieux, Perspectives et Enjeux du Développement; Edition TECHNIP, Paris, 2006.

[28] Egolfopoulos F.N., Du D.X., Law C.K. A study on ethanol oxidation kinetics in laminar premixed flames, flow reactors, and shock tubes, Symposium (International) on Combustion. 1992; 24, 833-841. 
[29]Liao SY, Jiang DM, Huang ZH, Zeng K, Cheng Q. Determination of the laminar burning velocities for mixtures of ethanol and air at elevated temperatures. Appl Therm Eng. 2007;27(2-3):374-380.

[30] Bradley D, Lawes M, Mansour MS. Explosion bomb measurements of ethanol-air laminar gaseous flame characteristics at pressures up to $1.4 \mathrm{MPa}$. Combust Flame. 2009;156(7):1462-1470.

[31] Veloo PS, Wang YL, Egolfopoulos FN, Westbrook CK. A comparative experimental and computational study of methanol, ethanol, and n-butanol flames. Combust Flame. 2010;157(10):1989-2004.

[32] Konnov AA, Meuwissen RJ, de Goey LPH. The temperature dependence of the laminar burning velocity of ethanol flames. Proc Combust Inst. 2011;33(1):1011-1019.

[33] Eisazadeh-Far K, Moghaddas A, Al-Mulki J, Metghalchi H. Laminar burning speeds of ethanol/air/diluent mixtures. Proc Combust Inst. 2011;33(1):1021-1027.

[34] Broustail G, Seers P, Halter F, Moréac G, Mounaim-Rousselle C. Experimental determination of laminar burning velocity for butanol and ethanol iso-octane blends. Fuel. 2011;90(1):1-6.

[35]Gülder ÖL. Burning velocities of ethanol-isooctane blends. Combust Flame. 1984; 56(3):261-268.

[36]van Lipzig JPJ, Nilsson EJK, de Goey LPH, Konnov AA. Laminar burning velocities of nheptane, iso-octane, ethanol and their binary and tertiary mixtures. Fuel. 2011;90(8):27732781.

[37] Dirrenberger P, Le Gall H, Bounaceur R, Herbinet O, Glaude PA, Konnov AA, BattinLeclerc F. Measurements of Laminar Flame Velocity for Components of Natural Gas. Energy Fuels. 2011;25(9):3875-3884. 
[38] Gillespie F, Metcalfe WK, Dirrenberger P, Herbinet O, Glaude PA, Battin-Leclerc F, Curran HJ. Measurements of flat-flame velocities of diethyl ether in air. Energy. 2012;43(1):140145.

[39] Bosschaart KJ, de Goey LPH. The laminar burning velocity of flames propagating in mixtures of hydrocarbons and air measured with the heat flux method. Combust Flame. 2004;136(3):261-269..

[40] Buda F, Bounaceur R, Warth V, Glaude PA, Fournet R, Battin-Leclerc F. Progress toward a unified detailed kinetic model for the autoignition of alkanes from C4 to C10 between 600 and 1200 K. Combust flame. 2005;142(1-2):170-186.

[41]Biet J, Hakka MH, Warth V, Glaude PA, Battin-Leclerc F. Experimental and Modeling Study of the Low-Temperature Oxidation of Large Alkanes. Energy Fuels. 2008;22(4):2258-2269.

[42] Herbinet O, Husson B, Ferrari M, Glaude PA, Battin-Leclerc F. Low temperature oxidation of benzene and toluene in mixture with n-decane. Proc Combust Institute, 2013; 34, 297-305.

[43] Bounaceur R, Da Costa I, Fournet R, Billaud F, Battin-Leclerc F. Experimental and modeling study of the oxidation of toluene. Int J Chem Kinet. 2005;37(1):25-49.

[44] R. J. Kee, F. M. Ruplay, J. A. Miller, Sandia Laboratories Report S 89-8009B. 1993.

[45] Muller C, Michel V, Scacchi G, Côme GM. Thergas - a Computer-Program for the Evaluation of Thermochemical Data of Molecules and Free-Radicals in the Gas-Phase. J Chim Phys. 1995;92(5):1154-1178.

[46] S.W. Benson, Thermochemical Kinetics, second ed., Wiley, New York, 1976.

[47] Wang H, Frenklach M. Transport properties of polycyclic aromatic hydrocarbons for flame modeling. Combust Flame. 1994;96:163-170. 
[48] Tran, LS; Glaude PA; Fournet R; Battin-Leclerc F. Experimental and modeling study of premixed laminar flames of ethanol. Energy \& Fuel, DOI: 10.1021/ef301628x. 
Table 1: Properties of the studied mixtures.

\begin{tabular}{ccccc}
\hline & $\begin{array}{c}\text { Commercial } \\
\text { gasoline } \\
\text { (TAE7000) }\end{array}$ & $\begin{array}{c}\text { Surrogate mixture } \\
(13.7 \% \text { (vol.) } n \text {-heptane, }\end{array}$ & $\begin{array}{c}\text { TAE7000 } \\
+\end{array}$ & $\begin{array}{c}\text { Surrogate } \\
\text { mixture } \\
+\end{array}$ \\
Formula & $\mathrm{C}_{6.76} \mathrm{H}_{12.48} \mathrm{O}_{0.08}$ & $\mathrm{C}_{7.34} \mathrm{H}_{12.43} \mathrm{O}_{0.00}$ & $\mathrm{C}_{5.43} \mathrm{H}_{10.67} \mathrm{O}_{0.33}$ & $\mathrm{C}_{5.82} \mathrm{H}_{10.61} \mathrm{O}_{0.28}$ \\
Estimated RON & 95.6 & 98.1 & 101.5 & 104.3 \\
Boiling point (K) & 363.52 & 378.34 & 360.14 & 370.69 \\
\hline
\end{tabular}




\section{FIGURE CAPTIONS}

Color figures in electronic versions only.

Figure 1: $\quad$ Scheme of the heat flux burner.

Figure 2: $\quad$ Laminar burning velocities of n-heptane at (a) 298, (b) 358, (c) $398 \mathrm{~K}$ and (d) comparison of the simulations and the present experimental results (points are experiments - present work and literature - and lines simulations).

Figure 3: $\quad$ Laminar burning velocities of iso-octane (a) 298, (b) 358, (c) $398 \mathrm{~K}$ and (d) comparison of the simulations and the present experimental results (points are experiments - present work and literature - and lines simulations).

Figure 4: $\quad$ Laminar burning velocities of toluene at 298, 358 and $398 \mathrm{~K}$ (points are experiments present work and literature - and lines simulations).

Figure 5: $\quad$ Laminar burning velocities of ethanol at 298, 358 and $398 \mathrm{~K}$ (points are experiments present work and literature - and lines simulations).

Figure 6: $\quad$ Experimental laminar burning velocities at $358 \mathrm{~K}$ of a commercial gasoline and of n-heptane, iso-octane, toluene and ethanol.

Figure 7: $\quad$ Laminar burning velocities at $358 \mathrm{~K}$ of a commercial gasoline and its surrogate mixture (points are experiments and lines simulations (only for the surrogate mixture)).

Figure 8: $\quad$ Laminar burning velocities at $358 \mathrm{~K}$ of a commercial gasoline, a commercial gasoline with addition of ethanol and a gasoline surrogate mixture with addition of ethanol (points are experiments and lines simulations (only for the surrogate mixture+ethanol)). 


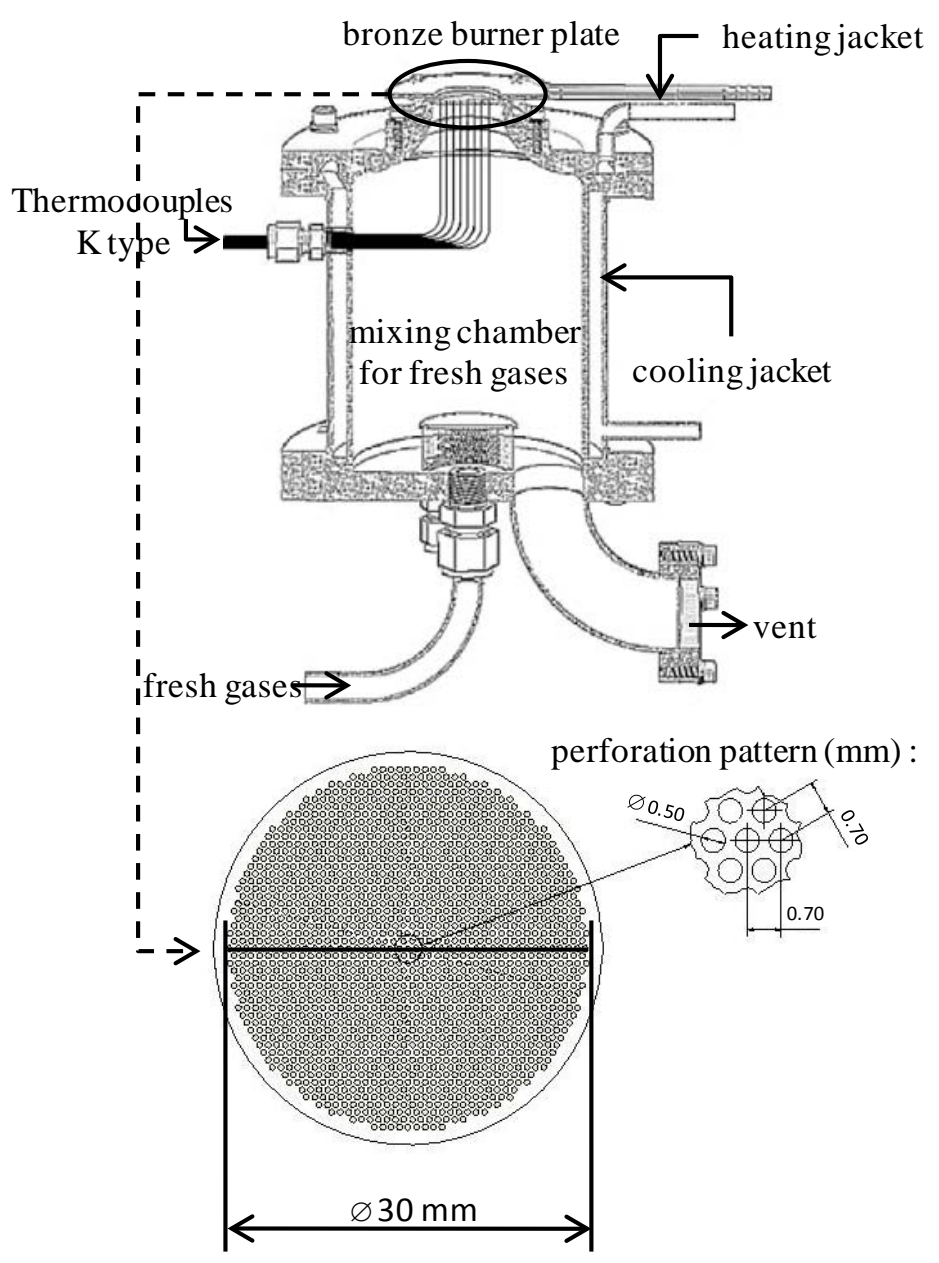

Figure 1: Scheme of the heat flux burner. 

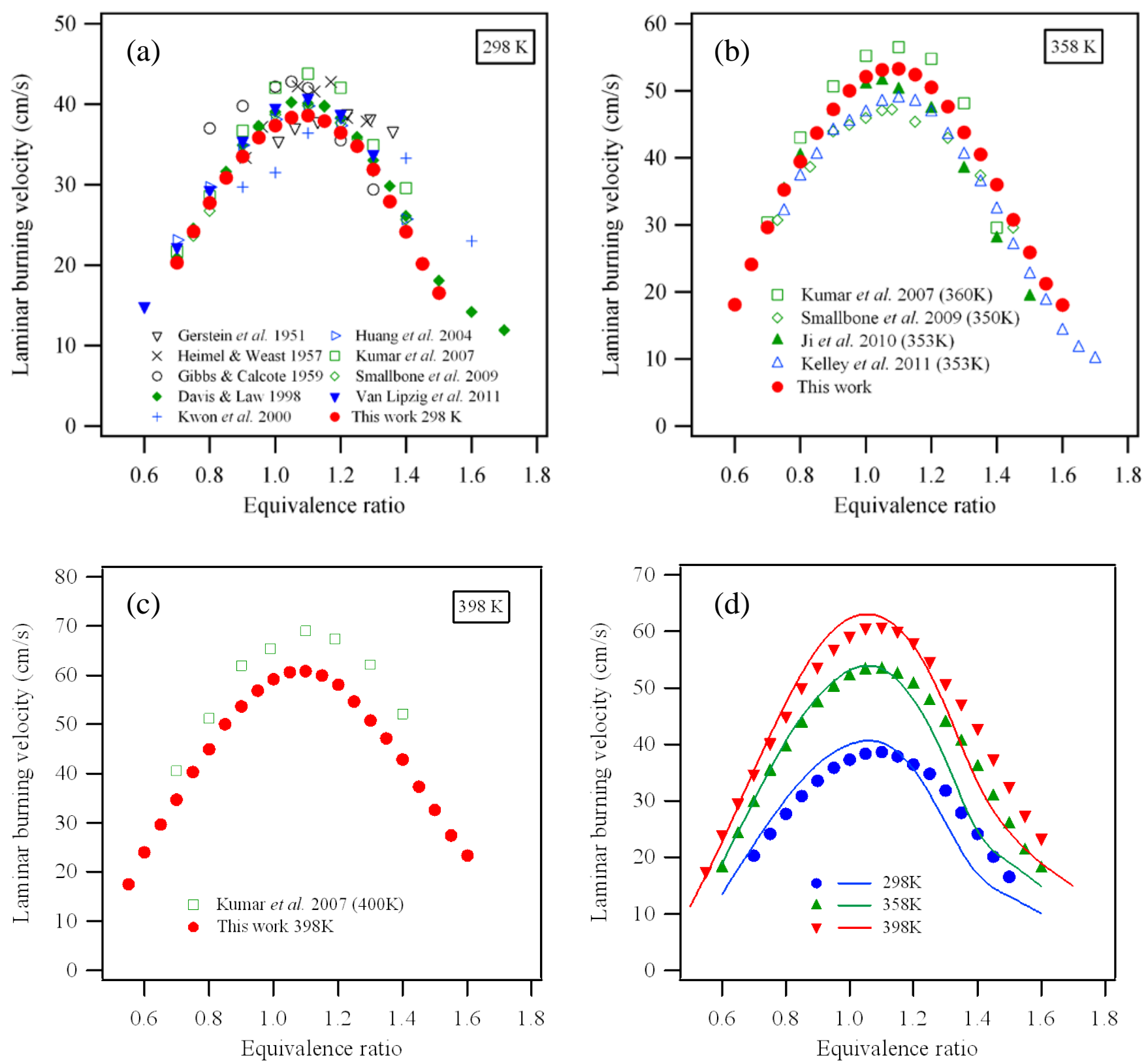

Figure 2: Laminar burning velocities of n-heptane at (a) 298, (b) 358, (c) $398 \mathrm{~K}$ and (d) comparison of the simulations and the present experimental results (points are experiments - present work and literature $[1][2][3][4][5][6][7][10][16][17][36]$ - and lines simulations). 

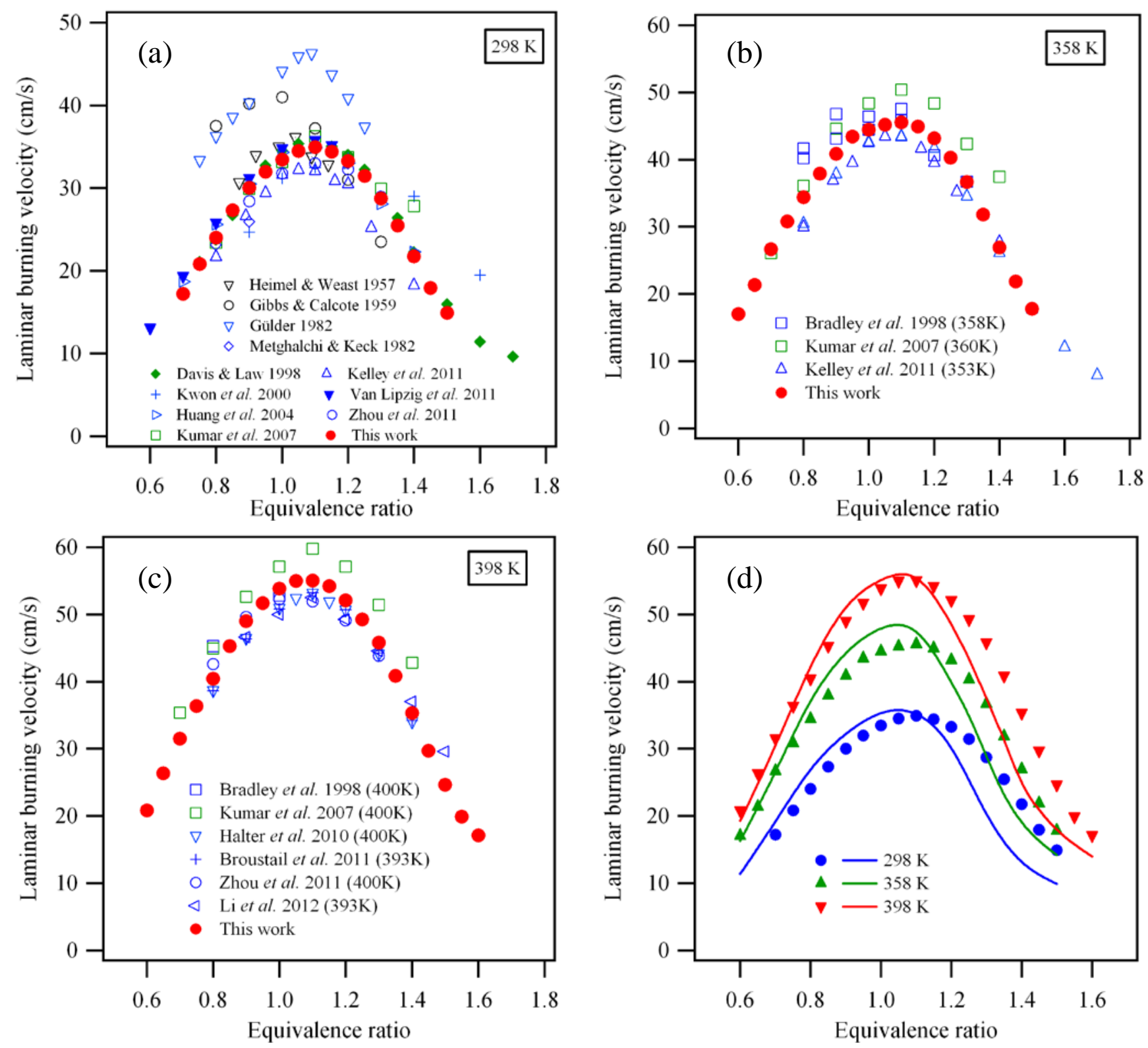

Figure 3: Laminar burning velocities of iso-octane (a) 298, (b) 358, (c) $398 \mathrm{~K}$ and (d) comparison of the simulations and the present experimental results (points are experiments - present work and literature [2][3][4][7][8][9][10][11][12][13][14][16][33][34][36] - and lines simulations). 

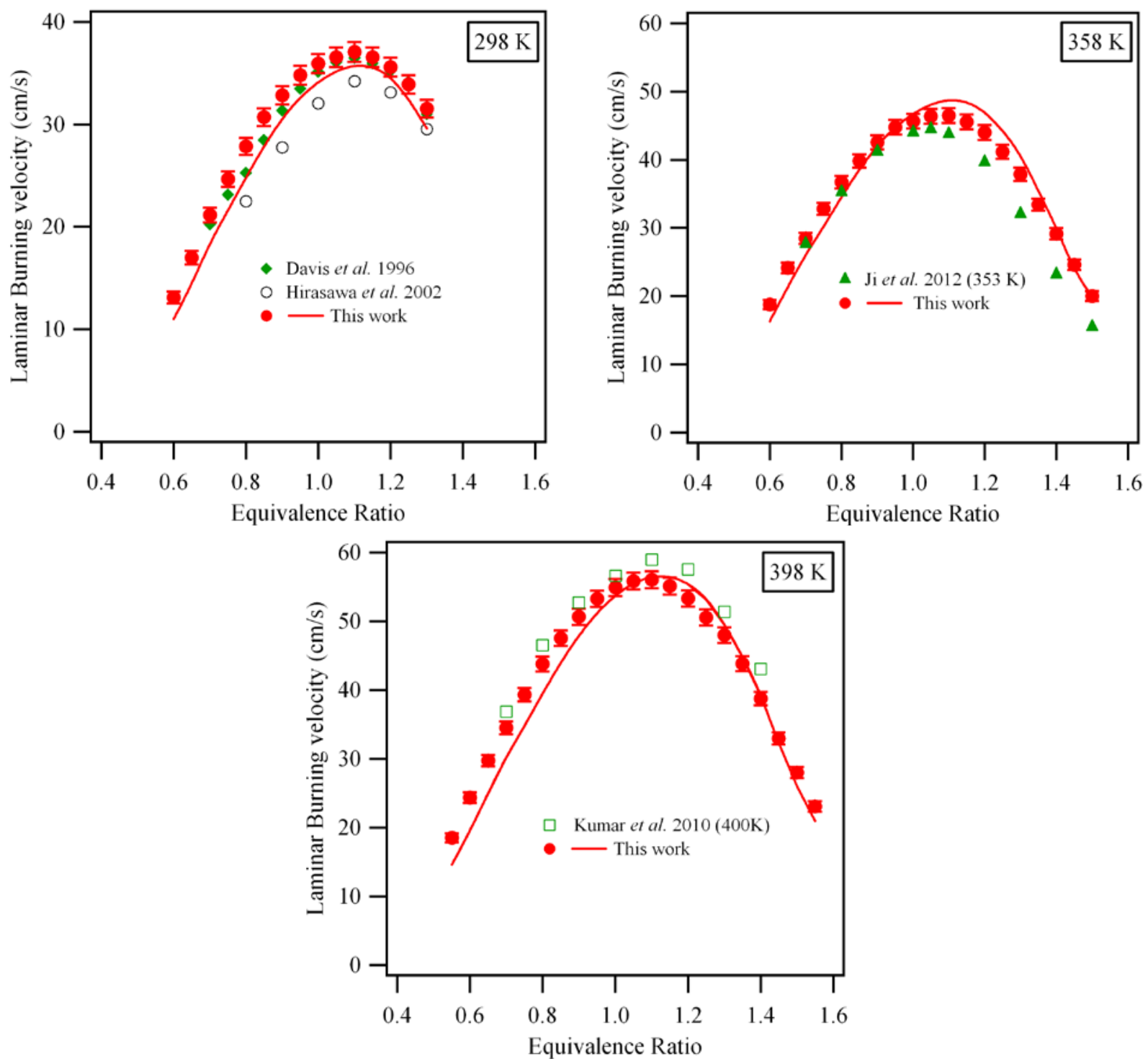

Figure 4: Laminar burning velocities of toluene at 298, 358 and $398 \mathrm{~K}$ (points are experiments - present work and literature [21][22][23][24] - and lines simulations). 

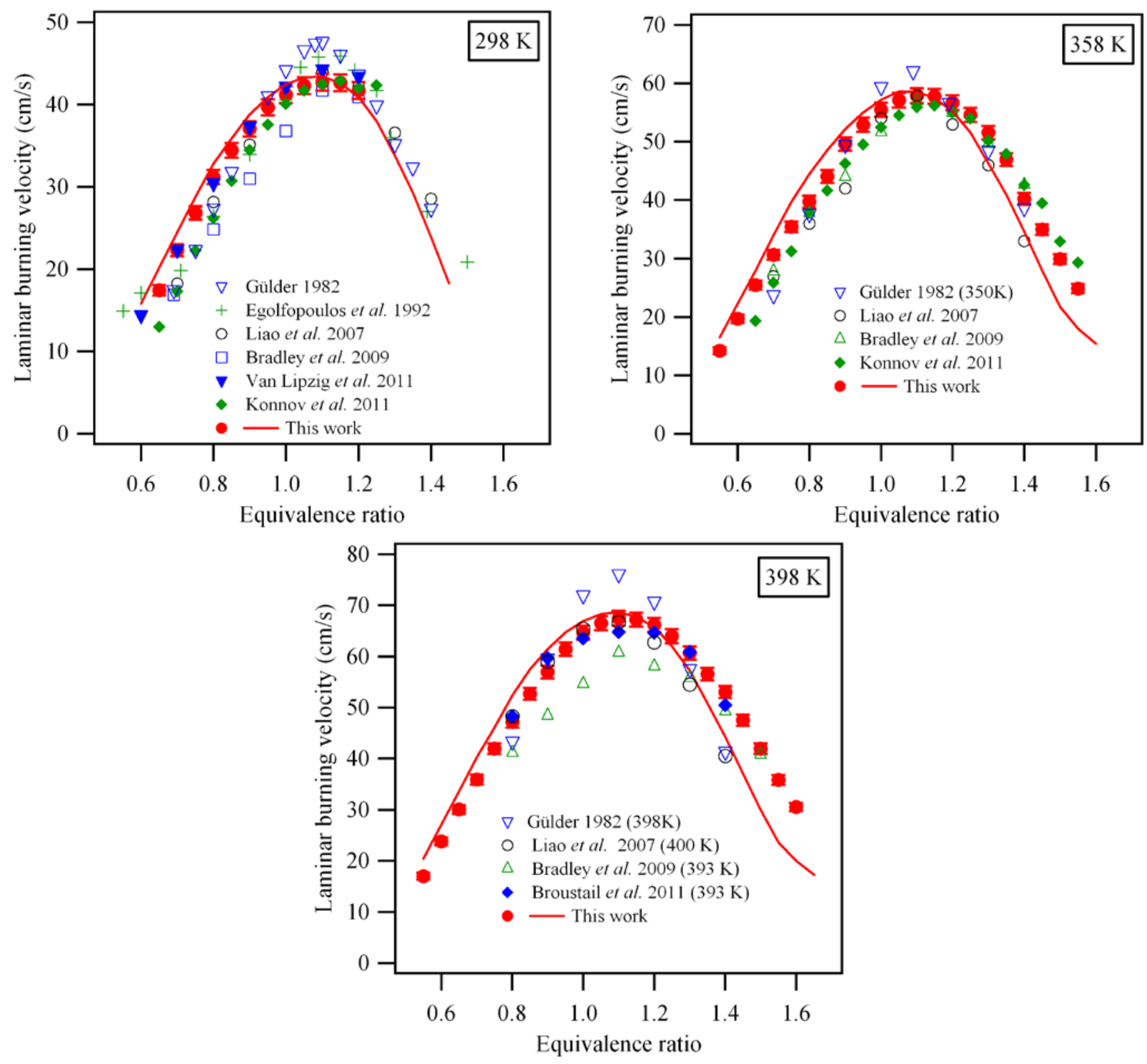

Figure 5: Laminar burning velocities of ethanol at 298, 358 and 398 K (points are experiments - present work and literature [8][28][29][30][32][34][36] - and lines simulations). 


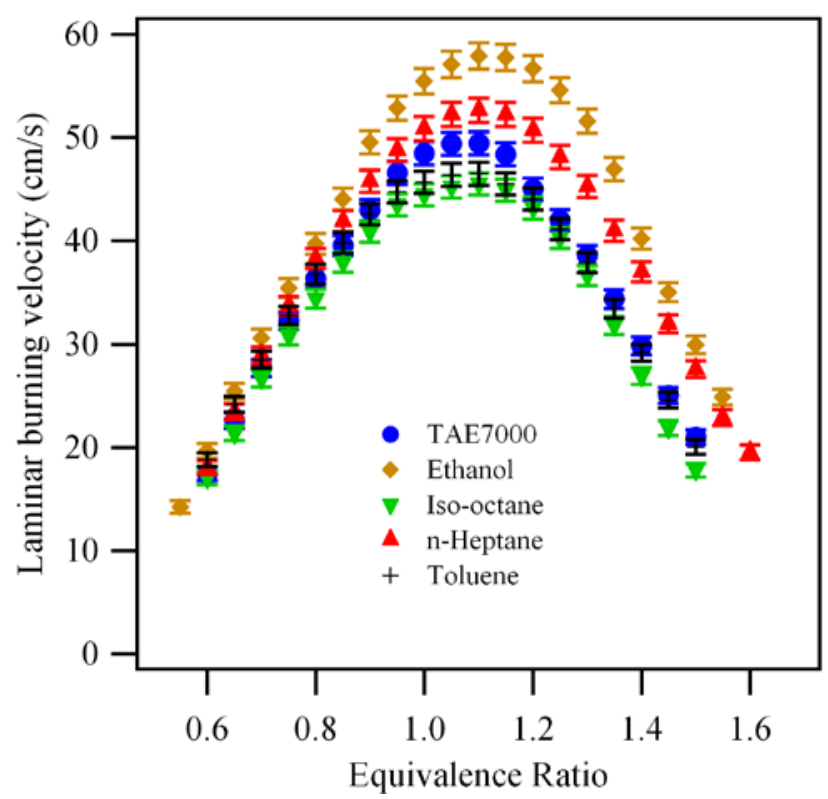

Figure 6: Experimental laminar burning velocities at $358 \mathrm{~K}$ of a commercial gasoline and of n-heptane, iso-octane, toluene and ethanol. 


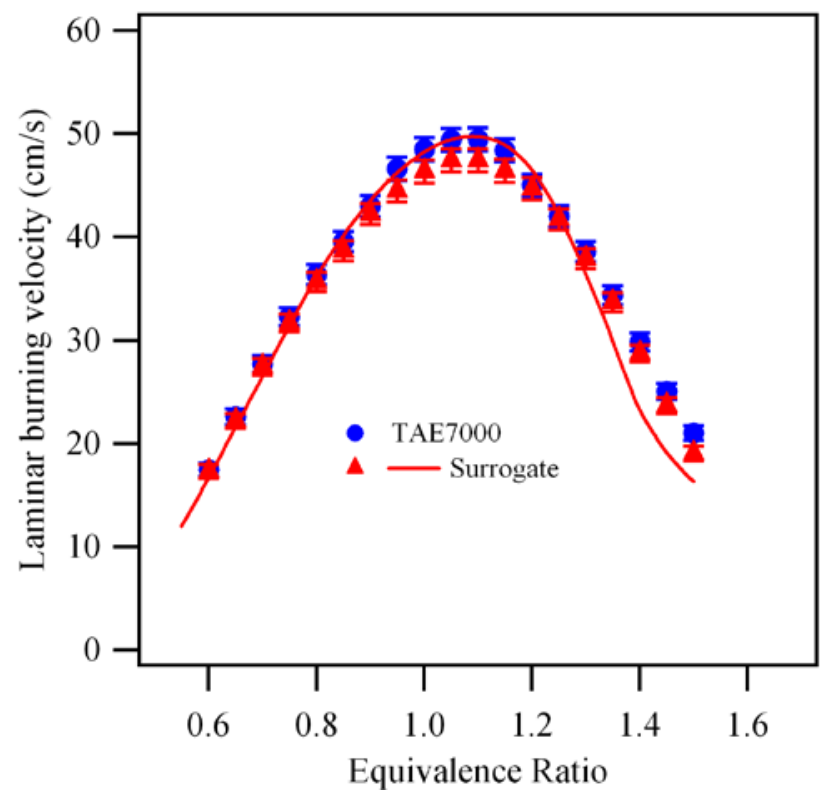

Figure 7: Laminar burning velocities at $358 \mathrm{~K}$ of a commercial gasoline and its surrogate mixture (points are experiments and lines simulations for the surrogate mixture. 


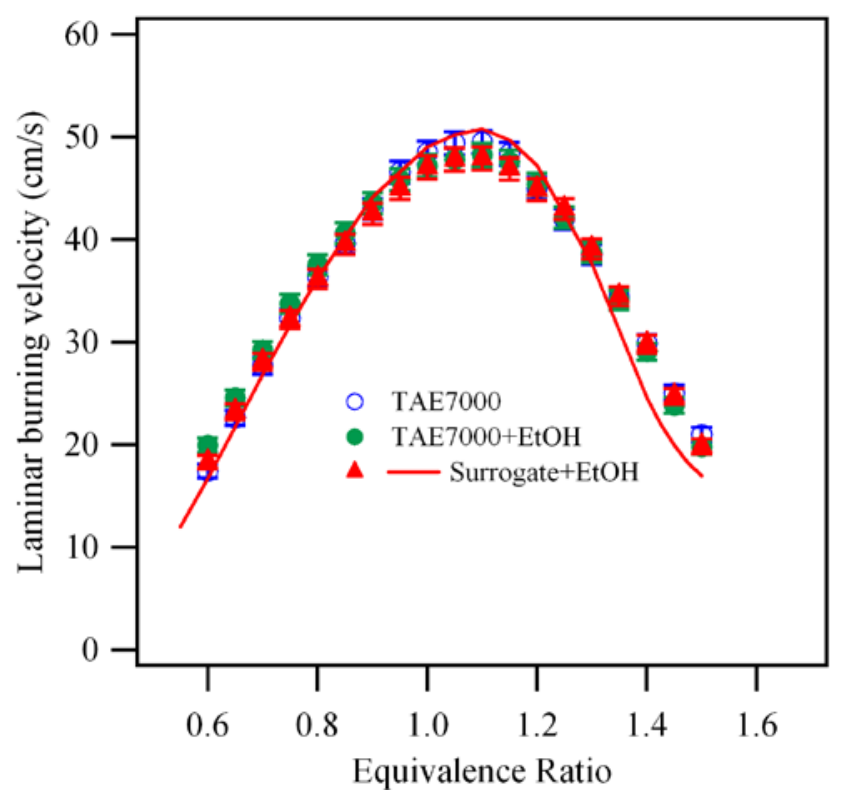

Figure 8: Laminar burning velocities at $358 \mathrm{~K}$ of a commercial gasoline, a commercial gasoline with addition of ethanol and a gasoline surrogate mixture with addition of ethanol (points are experiments and lines simulations (only for surrogate mixture+ethanol)). 
SUPPLEMENTARY MATERIAL:

Experimental for laminar burning velocities: data-Dirrenberger et al. 